Proceedings of the 11th Polish-Japanese Joint Seminar on Micro and Nano Analysis, Gniew, September 11-14, 2016

\title{
NiTi Shape Memory Marformed Alloy Studied by Electron Beam Precession TEM Orientation Mapping Method
}

\author{
P. Świec, M. ZubkO*, Z. LeKston And D. Stróż \\ Institute of Material Science, University of Silesia, 75 Pułku Piechoty 1a, 41-500 Chorzów, Poland

\begin{abstract}
Severe plastic deformation by cold-rolling in martensitic state was applied to $\mathrm{Ni}_{50.4} \mathrm{Ti}_{49.6}$ shape memory alloy. Received materials with 17, 20, 25, and 35\% deformation were further annealed at $450{ }^{\circ} \mathrm{C}$ for $15 \mathrm{~min}$. After such treatment hardness of this alloy increased significantly reaching 365 HV0.5 for highest deformation degree. Calorimetric studies revealed two-stage and two-step character of martensitic transformation occurring in all specimens. Nanocrystalline structure with average grain size 53, 34, 28, and $24 \mathrm{~nm}$ was obtained. In material with $35 \%$ of deformation amorphous regions containing a nuclei of $B 2$ parental phase with average size of $5 \mathrm{~nm}$ were observed. To determine the crystallographic orientation of observed nanograins and for better phase analysis, electron beam precession transmission electron microscopy orientation mapping was performed.
\end{abstract}

DOI: 10.12693/APhysPolA.131.1307

PACS/topics: 62.20.fg, 62.20.F-, 61.43.Dq, 61.66.Bi, 68.37.Ef, 62.25.-g, 64.70.Nd

\section{Introduction}

NiTi alloys are classified as intelligent materials due to exhibiting one- and two-way shape memory effects (SME) and superelasticity [1]. Shape memory effects which are observed in those alloys occur due to the reversible, thermoelastic martensitic transformation activated by heat, while superelasticity is associated with inverse martensitic transformation induced by an external stress [2].

Nanostructured NiTi alloys produced by plastic deformation exhibit high tensile strength and better shape recovery $[3,4]$. Phase transformation in these materials depends on their grain size. In case of NiTi alloys with grain size less than $150 \mathrm{~nm}$ there occurs $B 2 \rightarrow R \rightarrow B 19^{\prime}$ twostage transformation instead of one-stage $B 2 \rightarrow B 19^{\prime}$ [5]. Cold-rolling in martensitic state gives possibility of obtaining nanostructure in NiTi alloys. This is caused by amorphization of the material due to severe plastic deformation and further crystallization and recovery caused by proper post-deformation annealing leading to obtaining small-sized grains $[6,7]$.

Due to nanograins created in the NiTi alloys by the plastic deformation the transmission electron microscopy (TEM) is the ideal method to determine and study the obtained microstructure. Recent developments in the field allow also to study the crystallographic orientation at the nanoscale by means of electron beam precession TEM orientation mapping. Measurements are performed by recording a large number of diffraction patterns, point by point, from selected region of interest [8]. Recorded images are compared with the theoretically calculated diffraction images and based on that crystallographic orientation at a given point is calculated. The presented

*corresponding author; e-mail: maciej.zubko@us.edu.pl technique is similar to electron backscattered diffraction performed in microscale. Application of fast video camera allows to obtain crystallographic orientation maps from relatively large area in short time. Additional application of beam precession provides reduction of the dynamical effects which leads to better patterns comparison [9].

\section{Experimental}

$\mathrm{Ni}_{50.4} \mathrm{Ti}_{49.6}$ alloy was produced by melting and casting in Blazers VSG 10 vacuum induction furnace in Research and Development Laboratory for Aerospace Materials, Rzeszów University of Technology, and further subjected to hot forging. The received material had a rod shape of $\varnothing 3.5 \mathrm{~mm}$ diameter and it was cold rolled in martensitic state with rolling speed $\approx 5 \mathrm{~m} / \mathrm{min}$, cooled in liquid nitrogen after each rolling cycle. Materials with $17 \%$, $20 \%, 25 \%$, and $30 \%$ deformation were received. Postdeformation annealing at $450^{\circ} \mathrm{C}$ for 15 min was applied to as-deformed alloy.

The course of phase transitions and its characteristic temperatures were determined from differential scanning calorimetry (DSC) measurement. The measurements were carried out on DSC 1 Mettler Toledo in the temperature range from $-100^{\circ} \mathrm{C}$ to $+100{ }^{\circ} \mathrm{C}$ with $10^{\circ} \mathrm{C} / \mathrm{min}$ heating and cooling rate. The Vickers microhardness measurements were performed in order to determine the mechanical properties of all deformed materials samples. Transmission electron microscope (TEM) observations were conducted on JEOL JEM 3010 microscope with $300 \mathrm{kV}$ accelerating voltage and equipped with $2 \mathrm{k} \times 2 \mathrm{k}$ Orius $833 \mathrm{SC} 200 \mathrm{D}$ Gatan CCD camera. Microscope was additionally equipped with DigiStar electron beam precession attachment from NanoMEGAS. TEM specimen was prepared by "twin-jet" electro-polishing using $20 \% \mathrm{H}_{2} \mathrm{SO}_{4}-80 \% \mathrm{CH}_{3} \mathrm{OH}$ with $9 \mathrm{~V}$ polishing voltage $(\approx 20 \mathrm{~mA})$. 


\section{Results and discussion}

The performed cold rolling has significant influence on the phase transformation, which was shown by DSC measurements (Fig. 1). DSC curves registered during cooling cycle showed that studied NiTi alloy without plastic deformation possesses one step reversible phase transition from $B 2$ parent phase into $B 19^{\prime}$ martensitic phase. After plastic transformation the phase transition becomes the two-stage one with intermediate $R$ phase. DSC curves show spreading of transformation peak into three exothermic peaks located at $26.2^{\circ} \mathrm{C},-18.8^{\circ} \mathrm{C}$ and $46^{\circ} \mathrm{C}$ (see Table I). Higher enthalpy of high-temperature peak is caused by overlapping of two peaks with close temperature ranges, which is seen for $20 \%$ cold rolled sample. Two low-temperature peaks $M_{1}$ and $M_{2}$ are spreading and getting blurred with increasing deformation. Their enthalpy becomes lower in comparison to high-temperature peak. It can be observed that $M_{2}$ clearly smears out with increasing degree of deformation. DSC curves recorded during heating cycle exhibit one endothermic peak which splits into two peaks $A_{1}$ and $A_{2}$ with growing degree of cold rolling. For temperature of $27^{\circ} \mathrm{C}$ one blurred endothermic peak with low enthalpy occurs and it has not changed distinctly with ascending level of deformation.

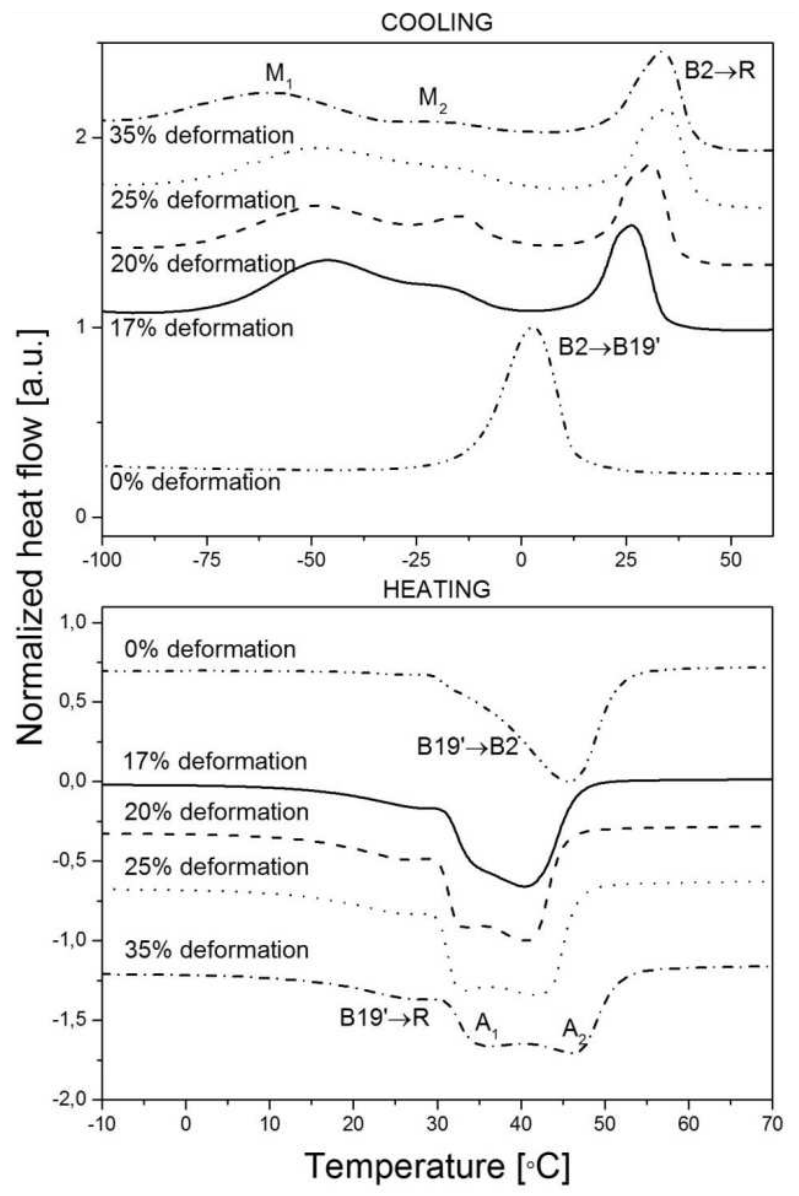

Fig. 1. DSC cooling (a) and heating (b) curves for cold rolled NiTi alloy.

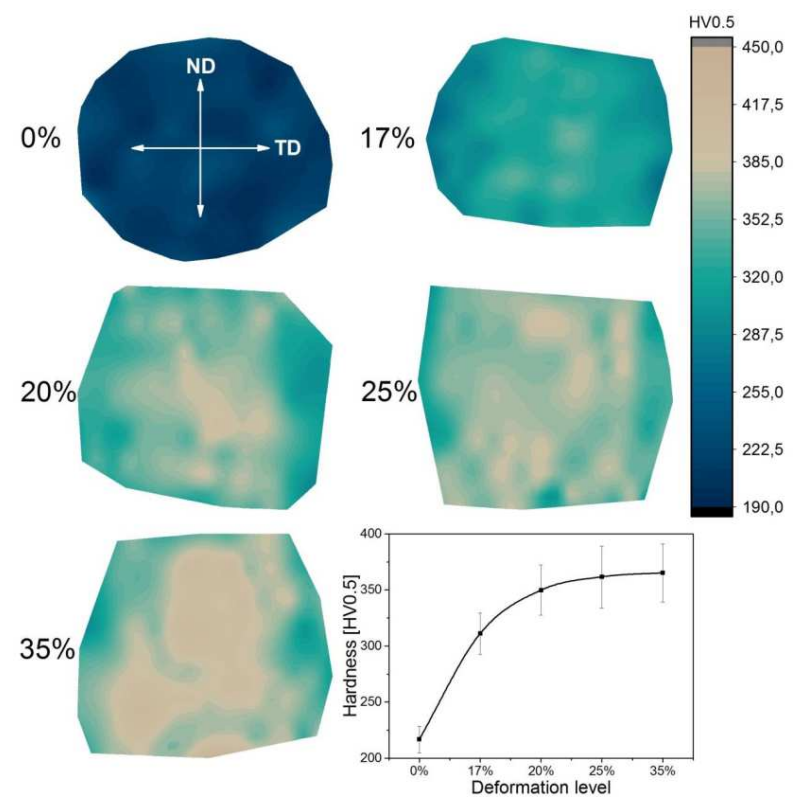

Fig. 2. Microhardness maps of material after cold rolling with average microhardness plot.

TABLE I

Data for peaks of DSC curves of cold rolled NiTi alloy.

\begin{tabular}{l|c|c|c|c|c}
\hline \hline & $0 \%$ & $17 \%$ & $20 \%$ & $25 \%$ & $35 \%$ \\
\hline \multicolumn{6}{c}{ Peak $1-$ cooling } \\
\hline$T_{\text {ONSET }}\left[{ }^{\circ} \mathrm{C}\right]$ & 12.93 & 33.77 & 37.62 & 41.68 & 41.62 \\
$T_{E N D S E T}\left[{ }^{\circ} \mathrm{C}\right]$ & -10.8 & 16.58 & 19.56 & 22.18 & 19.68 \\
$T_{P E A K}\left[{ }^{\circ} \mathrm{C}\right]$ & 3.04 & 26.5 & 30.74 & 34.49 & 33.62 \\
$\Delta H[\mathrm{~J} / \mathrm{g}]$ & 22.26 & 5.54 & 5.57 & 5.33 & 5.44 \\
\hline \multicolumn{6}{c}{ Peak $2-$ cooling } \\
\hline$T_{\text {ONSET }}\left[{ }^{\circ} \mathrm{C}\right]$ & - & -4.79 & -3.26 & -0.43 & -2.51 \\
$T_{E N D S E T}\left[{ }^{\circ} \mathrm{C}\right]$ & - & -70 & -77.26 & -78.57 & -91.57 \\
$T_{P E A K}\left[{ }^{\circ} \mathrm{C}\right]$ & - & -45.59 & -47.57 & -47.88 & -59.76 \\
$\Delta H[\mathrm{~J} / \mathrm{g}]$ & - & 8.91 & 7.23 & 7.26 & 5.26 \\
\hline \multicolumn{7}{c}{ Peak $3-$ heating } \\
\hline$T_{\text {ONSET }}\left[{ }^{\circ} \mathrm{C}\right]$ & 32.79 & 14.43 & 13.07 & 11.59 & 10.69 \\
$T_{E N D S E T}\left[{ }^{\circ} \mathrm{C}\right]$ & 51.36 & 46.81 & 44.92 & 46.71 & 51.55 \\
$T_{P E A K}\left[{ }^{\circ} \mathrm{C}\right]$ & 45.08 & 39.68 & 40.32 & 41.39 & 45.94 \\
$\Delta H[\mathrm{~J} / \mathrm{g}]$ & -21.75 & -19.07 & -19.26 & -18.57 & -17.52
\end{tabular}

The appearance of the intermediate $R$ phase after strong plastic deformation is associated with the increase in dislocation density in deformed alloys, caused by attraction of nearby dislocation by dislocation walls due to the impact of the stress field at their ends and caused increase in their thickness [10]. This happens because these walls are phase separation boundaries during martensitic transformation and their larger thickness hinders the occurrence of the phase transition. The reason for occurrence of two smeared peaks related to the martensitic transformation can be a different chemical composition in different areas of the sample as an effect of uneven distribution of stresses induced during plastic deformation, and thereby non-uniform recrystallization of the studied alloy. 


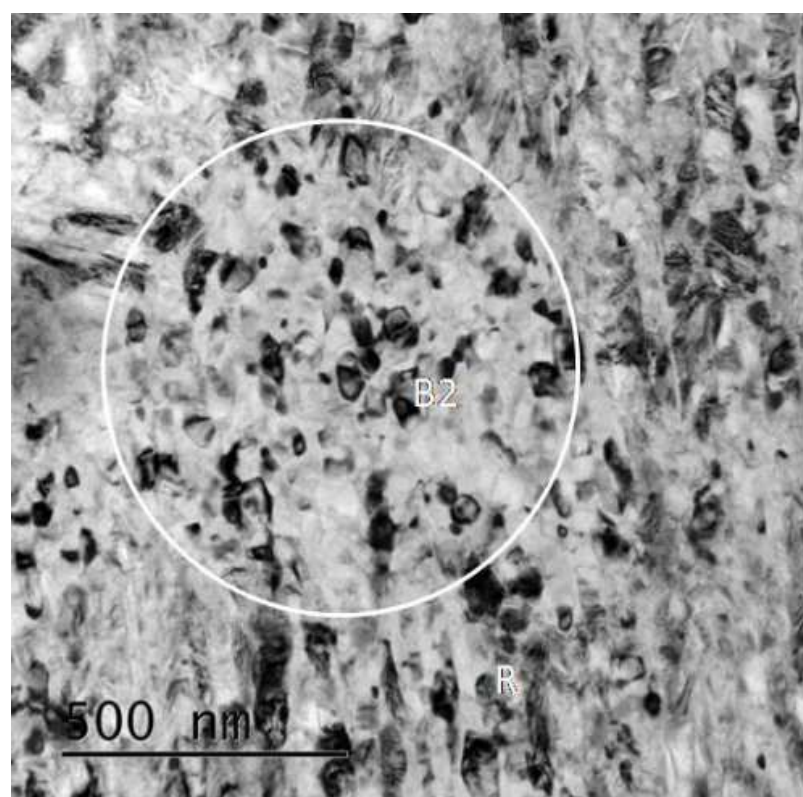

Fig. 3. TEM micrograph of mixture of fully recrystallized $B 2$ and $R$ phases grains in material after $25 \%$ cold rolling.
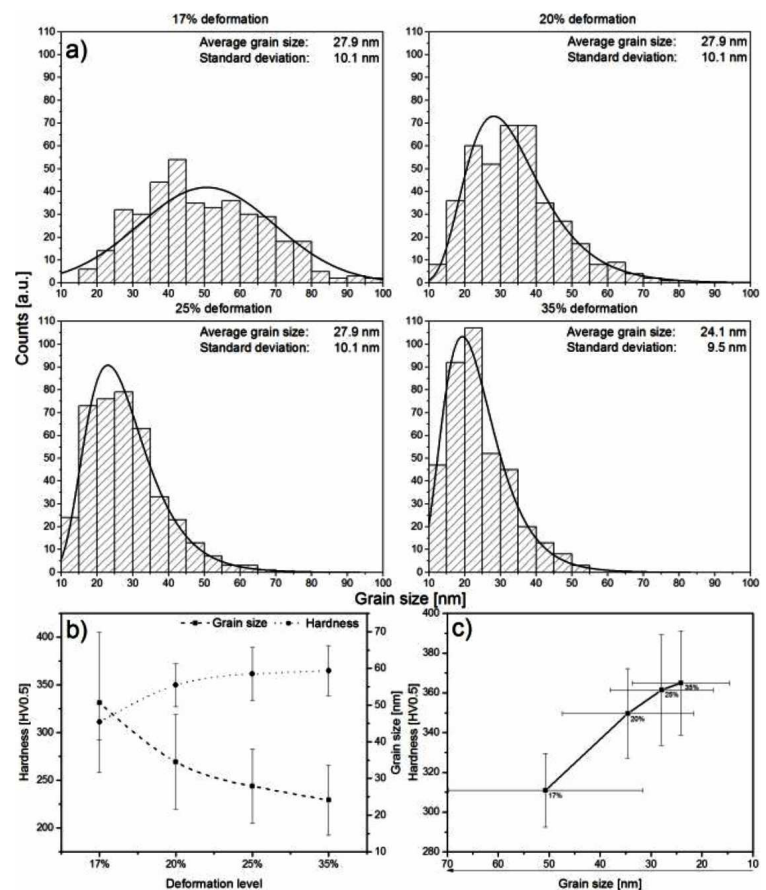

Fig. 4. Grain size histograms for all deformed samples (a) with grain size - hardness comparative (b,c).

Hardness maps were received by measuring Vickers microhardness for perpendicular sections of all deformed samples. These maps show increase in hardness with increasing reduction rate. It is clearly seen that the increase in hardness in normal direction (ND) is greater than in transverse direction (TD) (Fig. 2). Microhardness measurements showed significant changes in materials after cold rolling and annealing. 35\% cold rolled
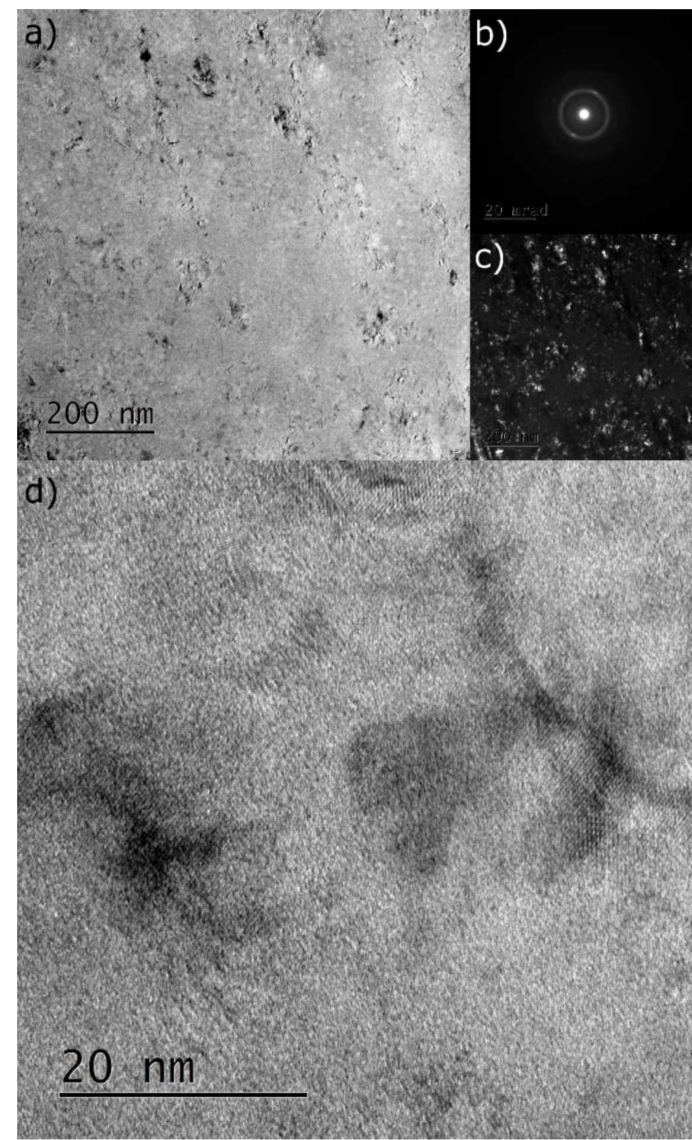

Fig. 5. Amorphous regions of $35 \%$ cold rolled material with $B 2$ crystallines observed on TEM in bright (a) and dark (b) field. Diffraction pattern (c) and HRTEM micrograph (d) reveals crystallines of $B 2$ phase.

material exhibited increase in the microhardness of $68 \%$ in comparison to the non-deformed alloy. Since the material has been strengthened mostly by grain refinement, which was confirmed by TEM studies, we can see that the highest forces were acting on the central part of the material during cold rolling which results in the largest deformation level. Hardness of studied alloy increased rapidly up to $20 \%$ cold rolled deformation. Furthermore, the increase in hardness is lower for higher deformation degrees which indicates great grain refinement. The average hardness of deformed materials reaches a maximum value of 365 HV0.5 to $35 \%$ cold rolled material.

Performed TEM observations revealed nanoscale crystallines of $B 2$ parental phase and intermediate $R$ phase in the studied samples (Fig. 3). It was observed that grain size of studied materials has decreased and their distribution converged with higher deformation degrees, however all cold rolled alloys had homogeneous mixture of both large and small grains. Grain size of $17 \%$ cold rolled material was distributed in the range of $15-80 \mathrm{~nm}$ and it converges with higher deformation applied to the material. For $35 \%$ cold rolled material grain size distribution is in the range of $10-3 \mathrm{~nm}$ (Fig. 4). Good coincidence of grain size with increase in alloys hardness is visible. 


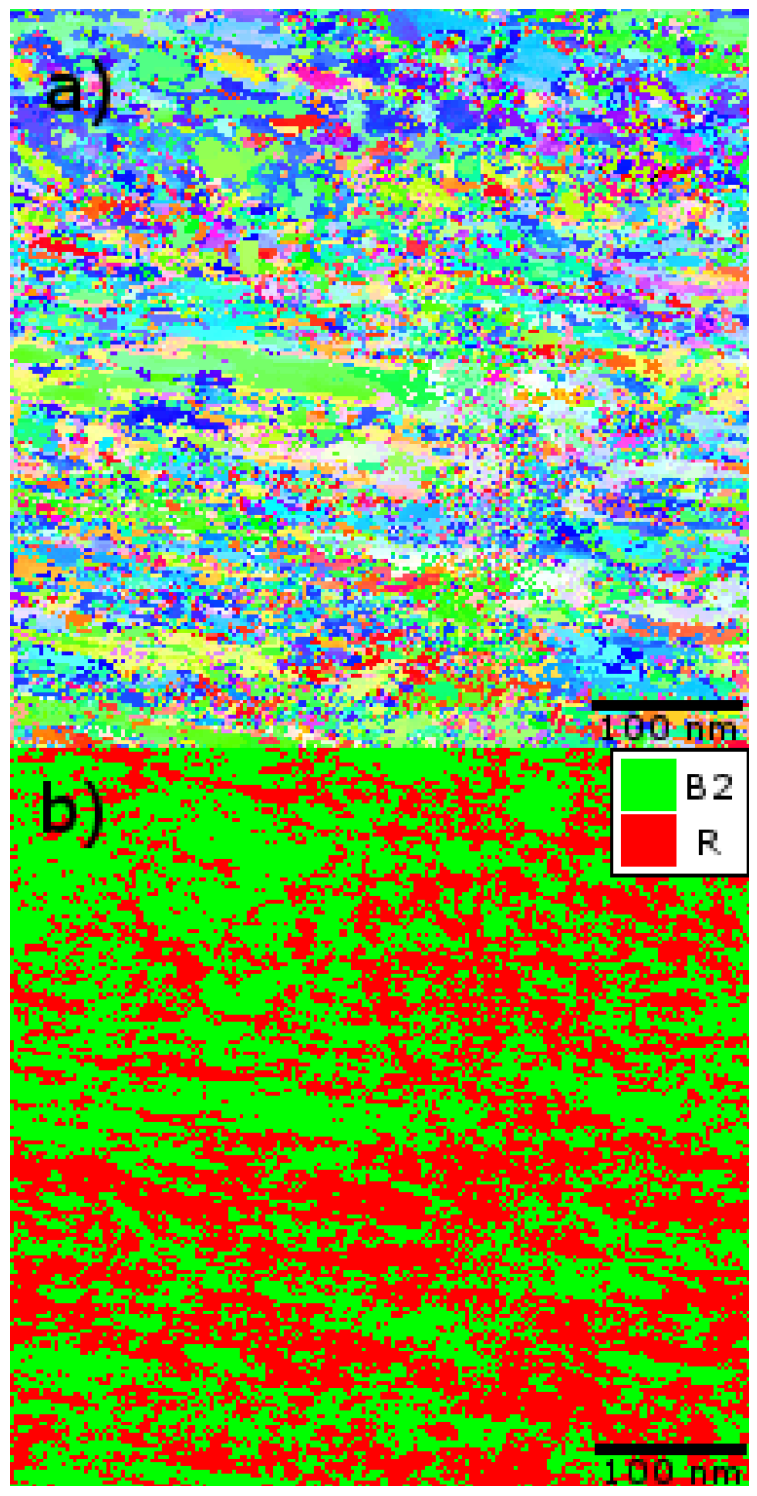

Fig. 6. TEM orientation map (a) with phase distribution map (b) of $35 \%$ cold rolled sample.

TEM observations revealed presence of amorphous phase in the studied material with highest deformation level (Fig. 5). Similar observations were showed by Sergueeva et al. in NiTi alloy after high pressure torsion [3]. $B 2$ phase crystallines observed in amorphous matrix are crystallization seeds with average size of $5 \mathrm{~nm}$ [11].

Recorded orientation map (Fig. 6) shows mainly nanograin structure with a few big elongated grains of $B 2$ phase with initiated polygonization mechanism. TEM orientation maps show great grain refinement, however larger grains with initiated polygonization mechanism can be seen. This confirms that stresses during forming are not uniform throughout the sample and proves the existence of different microscale areas which were affected with different stresses.

\section{Conclusions}

1. The material obtained by cold rolling of NiTi alloy in martensitic state leads to a nanocrystalline structure when applying large reduction in crosssection and post-deformation annealing in temperature higher than recrystallization temperature.

2. Studied alloy was strengthened significantly by applying severe plastic deformation (grain refinement). Maximum average hardness of $365 \mathrm{HV} 0.5$ was obtained in $35 \%$ cold rolled material.

3. Amorphous regions with $B 2$ nuclei were found in NiTi alloy after severe plastic deformation, thus it can be concluded that this material recrystallizes to $B 2$ phase. Recrystallized grains do not have preferred direction of growth.

4. Material has both severely deformed areas where nanograins and $B 2$ nuclei can be found and areas with larger recovered grains.

5. Electron beam precession TEM orientation mapping method is the most appropriate way to determine crystallographic orientation map of nanoscale grains thanks to the high-resolution of the experiment.

\section{References}

[1] T. Duerig, D. Stoeckel, D. Johnson, 0.1117/12.508666 Proc. SPIE 4763, 7 (2002).

[2] K. Otsuka, X. Ren, Progr. Mater. Sci. 50, 511 (2005).

[3] A.V. Sergueeva, C. Song, R.Z. Valiev, A.K. Mukherjee, Mater. Sci. Eng. A 339, 159 (2003).

[4] S.D. Prokoshkin, V. Brailovski, K.E. Inaekyan, V. Demersb, I.Yu. Khmelevskaya, S.V. Dobatkin, E.V. Tatyanin, Mater. Sci. Eng. A 481-482, 114 (2008).

[5] S.H. Chang, S.K. Wu, G.H. Chang, Scr. Mater. 52, 1341 (2005).

[6] D. Stróż, J. Palka, Z. Lekston, G. Dercz, Mater. Sci. Forum 738-739, 501 (2013).

[7] P. Świec, M. Zubko, Z. Lekston, D. Stróż, Acta Phys. Pol. A 130, 1063 (2016).

[8] A. Eggeman, P. Midgley, Adv. Imag. Electron Phys. 170, 1 (2012).

[9] R. Vincent, P. Midgley, Ultramicroscopy 53, 271 (1994).

[10] H. Morawiec, D. Stróż, T. Goryczka, D. Chrobak, Scr. Mater. 35, 485 (1996).

[11] M. Peterlechner, T. Waitz, H.P. Karnthaler, 566 Scr. Mater. 59, 566 (2008). 